\title{
Production and characterization of volatile compounds and phytase from potentially probiotic yeasts isolated from traditional fermented cereal foods in Nigeria
}

\author{
Omotade Richard Ogunremi ${ }^{1,2^{*}}$ (D) Renu Agrawal ${ }^{2}$ and Abiodun Sanni ${ }^{3}$
}

\begin{abstract}
Background: Probiotic strains are incorporated into food substrates to contribute to fermentation process. The technological suitability of such strains to improve the flavor and nutritional value of fermented food is strainspecific. Potentially probiotic yeasts isolated from Nigerian traditional fermented foods were assessed for production of volatile compounds by gas chromatography-mass spectrophotometry. Phytases were characterized for activity and stability at different $\mathrm{pH}(3-8)$ and temperatures $\left(25-50^{\circ} \mathrm{C}\right)$.

Results: A total of 45 volatiles compounds were identified from intracellular cell-free extracts of Pichia kluyveri LKC17, Issatchenkia orientalis OSL11, P. kudriavzevii OG32, P. kudriavzevii ROM11, and Candida tropicalis BOM21. They include alcohols (14), carbonyls (13), esters (10), and organic acids (8). Phenylethyl alcohol was the highest higheralcohol in Issatchenkia orientalis OSL11 (27.51\%). The largest proportion of esters was detected in P. kudriavzevii OG32 (17.38 \%). Pichia kudriavzevii OG32 and C. tropicalis BOM21 showed vigorous gowth in minimal medium supplemented with sodium phytate $\left(2 \mathrm{~g} \mathrm{~L}^{-1}\right)$. Extracellular phytases from P. kudriavzevii OG32 and Candida tropicalis BOM2 showed optimal activiy at pH $4.6(104.28 \mathrm{U})$ and pH $3.6(81.43 \mathrm{U})$ respectively.

Conclusions: Results obtained revealed species- and strain-specific potentials of the yeast strains to improve flavor and mineral bioavailability of fermented food products. Therefore, the application of these yeasts as starter cultures during food fermentation process is a very promising method to enhance the flavor profile and enhance mineral bioavailability in indigenous cereal-based fermented food products.
\end{abstract}

Keywords: Volatile compounds, Phytase, Probiotics, Fermented food, Yeast

\section{Background}

Probiotics are live microorganisms which, when administered in adequate amounts, confer health benefits on the host [1]. Indigenous fermented food products possess the potentials to meet the increasing demand for clean-label and health-beneficial foods by incorporating probiotic strains. Probiotics strains are typically selected from

\footnotetext{
* Correspondence: tadeogunremi@yahoo.com

'Department of Biological Sciences, First Technical University, Ibadan, Nigeria

${ }^{2}$ Food Microbiology Department, Central Food Technological Research

Institute, Mysore, India

Full list of author information is available at the end of the article
}

species of lactic acid bacteria and bifidobacteria [2]. However, the prospects of broader health benefits and delivery in unconventional food systems, including cereals, plant juices, and legumes have driven efforts toward exploring the larger microbial communities, including yeasts for microbial strains expressing interesting functionalities [3].

Several authors have reported the probiotic potentials of yeast strains from several indigenous fermented foods and beverages: burukutu, cheese, fura, gowe, kunu-zaki, mawe, nunu, kefir, ogi, olives, and wines [4-11]. Most of these yeasts are non-Saccharomyces species, including strains of Debaryomyces hansenii, Issatchenkia orientalis, 
Galactomyces geotrichum, Kluyveromyces marxianus, $K$. lactis, Pichia farinosa, P. anomala, P. kudriavzevii, and Yarrowia lipolytica. Their robust sizes (approx. $5 \times$ $10 \mu \mathrm{m})$, stress tolerance, antibiotic resistance that is not due to mobile genetic materials, non-pathogenic, nontoxigenic and non-allergenic nature, versatile enzyme profile, and production of several bioactive compounds contribute to the selection of yeasts as probiotics.

Technological suitability, including contribution to appealing flavor and improvement of nutritional value, are desirable for the selection of probiotic strains to be incorporated in non-dairy food systems, especially cereal models [12]. Volatile organic compounds (VOCs) are flavor-active metabolic products of organic compounds in living cells, especially yeasts through specific pathways such as Ehrlich, $\beta$-oxidation, and glycolytic pathways $[13,14]$. Recently, non-Saccharomyces yeasts are gaining attention as excellent producers of flavor compounds. They include some species of Candida, Galactomyces, Geotrichum, Hanseniaspora, Pichia, Saccharomycopsis, Saprochaete, Starmera, and Wickerhamomyces [13-15]. VOCs, including organic acids, esters, and higher alcohols determine the distinctive bouquet of the fermented product, contributing fruity, flowery, spicy, coffee to meaty nuance [14-18].

Phytate (Inositol hexaphosphate, IP6), the main form of phosphorous and a complex with dietary minerals (calcium, iron, magnesium, and zinc) in cereals, legumes, and nuts, is indigestible in the monogastric gastrointestinal tract $[19,20]$. Phytate is considered to be the most important anti-nutritional factor for the bioavailability of dietary minerals to consumers with diets exclusively based on cereals [21]. It is implicated in the global burden of iron deficiency and the attending complications particularly among women and children in low-income countries. Bioavailability of dietary minerals may be improved by using phytase, an enzyme that catalyzes the sequential hydrolysis of phytate [22, 23].

Phytase-active probiotic strains have the potential to improve the in situ and in vivo bioavailability of the divalent minerals, during food fermentation and in the gastrointestinal tracts respectively [20, 24]. Several authors have reported high phytase production by yeasts from various food sources, including Arxula adeninivorans, Hanseniaspora guilliermondii, I. orientalis, P. anomala, P. kudriavzevii, Saccharomyces cerevisiae, and S. pastorianus [20, 25-28]. However, the application of yeast phytases is dependent on the stability of the enzyme to evolving conditions during food fermentation and gastrointestinal transit. Therefore, broad $\mathrm{pH}$ and thermal stability are important properties for the enzyme.

In a previous study, we determined the probiotic potentials of yeasts isolated from some cereal-based Nigerian traditional fermented food product [8]. These yeast strains were evaluated as platform strains for the production of volatile compounds and phytase. In addition, the activity and stability of extracellular phytases from selected strains were determined for possible application during food fermentation and gastrointestinal transit.

\section{Methods \\ Reagents and materials}

Solvents and other chemicals were of analytical grade. Sodium phytate was obtained from Sigma Chemical Co. (St. Louis, MO).

\section{Yeast strains and culture conditions}

Yeast strains used in this study were selected based on the demonstration of probiotic potentials in a previous study [8]. They had been identified as Pichia kluyveri LKC17, Issatchenkia orientalis OSL11, P. kudriavzevii OG32, P. kudriavzevii ROM11, and Candida tropicalis BOM21 by sequencing D1/D2 region of large subunit of $26 \mathrm{~S}$ rDNA gene. The GenBank accession numbers are KJ472904, KJ472906, KJ472905, KJ472907, and KJ472908 respectively [8]. Yeast strains were routinely grown on yeast peptone dextrose (YPD) media (per liter; $10 \mathrm{~g}$ yeast extract, $20 \mathrm{~g}$ peptone, $20 \mathrm{~g}$ glucose) (HiMedia, Mumbai, India) at $30^{\circ} \mathrm{C}$ for $48 \mathrm{~h}$.

\section{Fermentation conditions and preparation of pellets}

A $1 \%(\mathrm{v} / \mathrm{v})$ of $24-\mathrm{h}$-old broth culture of each yeast strain was inoculated in YPD broth and incubated at $30^{\circ} \mathrm{C}$ till exponential phase $(24 \mathrm{~h})$. A $10 \mathrm{~mL}$ broth culture was centrifuged at $7500 \mathrm{rev} \min ^{-1}$ and $4{ }^{\circ} \mathrm{C}$ for $10 \mathrm{~min}$, the supernatant was discarded and yeast cells were washed twice with sterile saline water $(0.85 \% \mathrm{NaCl})$.

\section{Analysis of volatile compounds}

Extraction of volatile compounds from yeast cells

Extraction of volatile compounds was done by liquidliquid extraction [29]. A suspension of yeast cells in $10 \mathrm{~mL}$ of dichloromethane was disrupted for 10 min with mortar and pestle at $5{ }^{\circ} \mathrm{C}$ and shaken vigorously in $100 \mathrm{~mL}$ separatory funnel for $2 \mathrm{~min}$. The solvent phases were pooled into a dry test tube and dried with $0.5 \mathrm{~g}$ of anhydrous sodium sulfate. The extract was concentrated in a graduated tube to $500 \mu \mathrm{L}$ by shaking in a water bath $25^{\circ} \mathrm{C}$.

\section{Separation, identification, and quantification of volatile compounds}

Volatile compounds in the concentrated extract were separated and detected by using a gas chromatographymass spectrophotometer (GC-MS) (Perkin Elmer, Waltham, USA). The separation of volatiles was carried out in an ELITE 1 non-polar capillary column (30 m X 0.25 $\mathrm{mm}$ (ID); $0.25 \mu \mathrm{m}$ film thickness). One microliter of extract was injected (split ratio 1:10) into the injection port 
and carried along the capillary column by helium gas (99.9\%) at a flow rate of $1 \mathrm{~mL} \mathrm{~min}^{-1}$. The oven temperature was held at $100^{\circ} \mathrm{C}$ for $6 \mathrm{~min}$, heated at $4^{\circ} \mathrm{C}$ $\mathrm{min}^{-1}$ to $150^{\circ} \mathrm{C}$, then at $8^{\circ} \mathrm{C} \mathrm{min}{ }^{-1}$ to $220^{\circ} \mathrm{C}$ and held at $220^{\circ} \mathrm{C}$ until an approximate run time of $40 \mathrm{~min}$.

The mass spectrophotometer was operated in the electron impact mode and mass spectra were taken using an ionization voltage of $70 \mathrm{eV}$. The mass scan range was 40-400 AMU, with a scanning speed of $0.2 \mathrm{~s}$. Data acquisition and generation of chromatograms and mass spectra were done with the TurboMass software [29].

The identification of volatile compounds was performed by comparing the mass spectra with the standard spectra database from the NIST Ver. 2.1 2009 Mass Spectra Library. The proportion of each compound was calculated by comparing the peak area with the total area.

\section{Phytase analysis}

\section{Screening for phytase production}

The test yeast strains were screened for phytase production by determining their ability to grow in a minimal medium with phytic acid as the sole source of phosphorus [27]. Yeast cells were harvested from $1 \mathrm{~mL}$ broth culture by centrifugation $\left(7500 \mathrm{rev} \mathrm{min}^{-1}\right.$ and $4{ }^{\circ} \mathrm{C}$ for $15 \mathrm{~min}$ ) and cells were resuspended in $0.5 \mathrm{~mL}$ of sterile saline water. A $1 \%(\mathrm{v} / \mathrm{v})$ of each cell suspension was inoculated into respective liquid growth media; phosphatefree minimal medium (per liter: $15 \mathrm{~g}$ glucose, $5 \mathrm{~g}$ $\mathrm{NH}_{4} \mathrm{NO}_{3}, 2 \mathrm{~g} \mathrm{CaCl}_{2}, 0.5 \mathrm{~g} \mathrm{MgSO}_{4} .7 \mathrm{H}_{2} \mathrm{O}, 0.5 \mathrm{~g} \mathrm{KCl}, 0.01$ $\mathrm{g} \mathrm{FeSO}_{4} \cdot 7 \mathrm{H}_{2} \mathrm{O}, 0.01 \mathrm{~g} \mathrm{MnSO}_{4} \cdot \mathrm{H}_{2} \mathrm{O}$ ) as negative control, phosphate-containing minimal medium (phosphate-free minimal medium $+3 \mathrm{~g} \mathrm{~L}^{-1} \mathrm{KH}_{2} \mathrm{PO}_{4}$ ) as positive control and phytate-containing minimal medium (phosphatefree minimal medium $+3 \mathrm{gL}^{-1}$ sodium phytate) as test. The broth cultures were incubated at $30^{\circ} \mathrm{C}$ for $48 \mathrm{~h}$. Yeast growth was determined after gentle agitation and measurement of the optical density at $600 \mathrm{~nm}$ [27]. This was carried out in triplicates and relative growth and was calculated using the formula below:

$$
\text { Relative growth }(\%)=\frac{A i}{A o} \times 100
$$

where $A o$ is the absorbance in phosphate-containing minimal medium and $A i$ is the absorbance in either phosphate-free or phytate-containing minimal medium.

\section{Extracellular phytase extraction}

A $1 \%(\mathrm{v} / \mathrm{v})$ of an overnight culture of selected yeast strain was inoculated in a 250-mL Erlenmeyer flask, containing $100 \mathrm{ml}$ of minimal salt medium (per liter: $15 \mathrm{~g}$ glucose, $\quad 5 \mathrm{~g}$ Na-phytate, $\quad 5 \mathrm{~g} \quad \mathrm{NH}_{4} \mathrm{NO}_{3}, \quad 0.5 \mathrm{~g}$ $\mathrm{MgSO}_{4} .7 \mathrm{H}_{2} \mathrm{O}, 2 \mathrm{~g} \mathrm{CaCl}_{2}, 0.5 \mathrm{~g} \mathrm{KCl}, 0.01 \mathrm{~g} \mathrm{FeSO}_{4} .7 \mathrm{H}_{2} \mathrm{O}$, $0.01 \mathrm{MnSO}_{4} \cdot \mathrm{H}_{2} \mathrm{O}$ ). The medium was incubated in a shaking water bath $\left(1700 \mathrm{rev} \mathrm{min}^{-1}\right)$ at $30^{\circ} \mathrm{C}$ for $48 \mathrm{~h}$ Culture supernatant with extracellular phytase was obtained after the centrifugation $\left(7500 \mathrm{rev} \mathrm{min}^{-1}\right.$ and $4{ }^{\circ} \mathrm{C}$ for $10 \mathrm{~min}$ ) of the broth culture and used for extracellular phytase assay [27].

\section{Phytase activity assay at different $\mathrm{pH}$}

Phytase activity at different $\mathrm{pH}(3-8)$ was assayed by measuring the amount of inorganic phosphate liberated from sodium phytate in different buffer systems; $0.2 \mathrm{M}$ citrate buffer $(\mathrm{pH} 3.0$ and 6.0), $0.2 \mathrm{M}$ acetate buffer $(\mathrm{pH}$ 3.5-5.5) and 0.2 M Tris-HCl buffer ( $\mathrm{pH} 7.0-8.0)$. The reaction mixture consisted of $0.8 \mathrm{~mL}$ of the respective buffer containing $2 \mathrm{mM}$ of Na-phytate and $0.2 \mathrm{~mL}$ of enzyme extract. Negative controls were prepared from enzyme extracts mixed with respective buffer without phytic acid. Reaction mixtures were incubated at $37^{\circ} \mathrm{C}$ and stopped after $30 \mathrm{~min}$ by adding $1 \mathrm{~mL}$ of $10 \%$ trichloracetic acid (TCA). The blank was prepared by adding 10\% TCA solution before the substrate was added. Determination of liberated inorganic phosphate was performed according to the ferrous sulfate-ammonium molybdate method [30]. Phosphate standard curve was prepared with inorganic phosphate $\left(\mathrm{KH}_{2} \mathrm{PO}_{4}\right)$ (0-5 $\left.\mathrm{mmol} \mathrm{mL} \mathrm{m}^{-1}\right)$. One unit $(\mathrm{U})$ of phytase activity was defined as that which liberated one micromole of phosphate per minute under the assay conditions [26].

\section{Phytase stability to different $\mathrm{pH}$ and temperature}

Phytase was incubated at $\mathrm{pH} 3-8$ for $1 \mathrm{~h}$ at $4{ }^{\circ} \mathrm{C}$ and different temperatures $\left(20-50{ }^{\circ} \mathrm{C}\right)$ for $1 \mathrm{~h}$. The residual phytase activity was assayed and relative activity was calculated [26].

\section{Results}

Volatile compounds produced by probiotic yeasts

Volatile organic compounds produced by test probiotic yeast strains are shown in Table 1. A total of 45 volatile compounds were identified and broadly categorized into four groups, including organic acids (8), alcohols (14), carbonyls (13) and esters (10). Pichia kluyveri LKC17 produced eighteen volatile compounds and carbonyls accounted for the highest number (7) and largest proportion (36\%). The highest variety of alcohol was produced by I. orientalis OSL11. Phenyl ethyl alcohol was noted to be the largest proportion of alcohol produced by $I$. orientalis OSL11, P. kudriavzevii OG32, and $P$. kudriavzevii ROM 11. The largest proportion of esters was detected in P. kudriavzevii OG32 and it accounted for $17.38 \%$ of the total volatile compounds produced by the strain (Table 1). 
Table 1 Analysis of volatile compounds produced by probiotic yeast strains

Odor description $^{\mathbf{a}}$

(\%) yield

\begin{tabular}{lllll}
\hline P. kluyveri & I. orientalis & P. kudriavzevii & P. kudriavzevii & C. tropicalis
\end{tabular}

$\begin{array}{lllll}\text { LKC17 } & \text { OSL11 } & \text { OG32 } & \text { ROM } 11 & \text { BOM21 }\end{array}$

\begin{tabular}{ll}
\hline RT (min) & Compound name \\
& \\
\hline & Acids \\
4.72 & Dimethyl-propanoic acid \\
22.12 & 1,2-Benzenedicarboxylic acid \\
22.83 & Decanoic acid \\
25.86 & 9-Hexadecenoic acid \\
26.22 & N-Hexadecanoic acid \\
26.52 & Octadecenoic acid \\
28.54 & Erucic acid \\
28.85 & Nonadecanoic acid \\
& Total acids (8) \\
& Higher alcohols \\
3.37 & 1-Phenyl-1propanol \\
4.67 & Phenyl ethyl alcohol \\
18.99 & DL-3,4-Dimethyl-3-4-hexanediol \\
19.00 & 1-Decanol \\
21.30 & 2-Ethyl-1-decanol \\
21.35 & 2-Hexyl-1-octanol \\
21.88 & 4-Piperidine methanol \\
22.56 & 1-Heptadecanol \\
23.59 & 1-Dodecanol \\
23.63 & Cis-1,2-cyclohexanediol \\
27.15 & Nonacosanol \\
27.17 & 1-Chloro-ethanol \\
30.71 & 1-Pentacosanol \\
31.42 & (S)-3,4-Dimethylpentanol \\
&
\end{tabular}

Fatty
Fatty
Waxy fatty
Fatty

Floral, balsamic

Floral, rosey

Fatty, floral, orange

Fans

Fatty, honey, coconut

$\begin{array}{lll}1.79 \pm 0.04 & N D & N D \\ N D & 0.30 \pm 0.00 & N D \\ N D & N D & N D \\ N D & N D & 5.66 \pm 0.31 \\ 20.38 \pm 3.21 & 9.67 \pm 0.11 & 10.60 \pm 2.33 \\ 0.80 \pm 0.00 & N D & N D \\ 12.50 \pm 1.48 & N D & N D \\ N D & N D & N D\end{array}$

\subsection{7 (4)}

9.97 (2)

$16.26(2)$

ND

ND

ND

ND

ND

Fatty honey, coconut

ND

ND ND

ND

$27.51 \pm 3.76$

ND

$0.67 \pm 0.01$

ND

ND

$0.39 \pm 0.00$

ND

$3.17 \pm 0.00$

$25.69 \pm 3.01$

ND

ND

$0.21 \pm 0.00$

ND

$9.49 \pm 0.45$

ND

$\mathrm{ND}$

$3.88 \pm 0.00$

ND

ND

ND

$3.45 \pm 0.00$

ND

16.11 (3)

29.57 (2)

$0.49 \pm 0.00$

ND

$17.38 \pm 1.17$

$0.40 \pm 0.00$

$2.16 \pm 0.42$

ND

ND

$1.02 \pm 0.00 \quad N D$

$\mathrm{ND}$

ND

ND

ND $\quad 2.50 \pm 0.01 \quad N D$

$1.22 \pm 0.03$

ND

$\mathrm{ND}$

ND

ND

$0.32 \pm 0.01$

ND

$2.52 \pm 0.00$

ND

ND

ND

ND

ND

ND

ND

ND

$\mathrm{ND}$

ND

ND

ND

17.38 (1)

$0.35 \pm 0.00$

ND

ND

$2.37 \pm 0.23$

ND

$1.03 \pm 0.00$

$8.29 \pm 0.07$

4.37 (4)

32.58 (7)

ND

Total alcohols (14)

Carbonyls

$\begin{array}{ll}22.32 & \text { E-14-Hexadecenal } \\ 23.13 & \text { Cis-oxacyclohexadecan-2-one } \\ 23.15 & \text { Hexanal } \\ 23.71 & \text { Heptanal } \\ 24.97 & \text { Pyrrolo(1,2A)piperazine-1,4-dione } \\ 25.00 & \text { 1,2,5-Trimethyl-5-piperid-4-one } \\ 25.11 & \text { Cyclohexanone } \\ 25.17 & \text { 3-Buten-2-one } \\ 25.88 & \text { 2-Heptadecenal } \\ 28.45 & \text { E-11 Hexadecenal } \\ 28.46 & \text { 9-Octadecenal } \\ 31.62 & \text { Decanal } \\ 31.78 & \text { Dodecanal }\end{array}$

Total carbonyls (13)

Esters

\begin{tabular}{|c|c|c|c|c|}
\hline $4.64 \pm 0.06$ & $0.31 \pm 0.01$ & ND & ND & ND \\
\hline $9.57 \pm 0.71$ & ND & ND & ND & ND \\
\hline ND & ND & ND & $8.27 \pm 0.59$ & ND \\
\hline $1.67 \pm 0.00$ & ND & ND & $1.50 \pm 0.02$ & ND \\
\hline ND & $11.64 \pm 0.64$ & $6.76 \pm 0.21$ & $9.52 \pm 0.00$ & $19.28 \pm 2.00$ \\
\hline $10.07 \pm 0.89$ & ND & ND & ND & ND \\
\hline ND & $6.12 \pm 0.04$ & $11.53 \pm 4.00$ & ND & ND \\
\hline $5.63 \pm 0.03$ & ND & ND & ND & ND \\
\hline $2.35 \pm 0.10$ & $5.25 \pm 0.00$ & ND & ND & ND \\
\hline ND & ND & ND & $15.89 \pm 4.66$ & ND \\
\hline ND & $14.02 \pm 1.00$ & $16.63 \pm 3.11$ & ND & ND \\
\hline ND & $3.61 \pm 0.07$ & ND & ND & ND \\
\hline $2.07 \pm 0.05$ & ND & ND & ND & ND \\
\hline $36.0(7)$ & $40.95(6)$ & $34.92(3)$ & $35.18(4)$ & $19.28(1)$ \\
\hline
\end{tabular}


Table 1 Analysis of volatile compounds produced by probiotic yeast strains (Continued)

\begin{tabular}{|c|c|c|c|c|c|c|c|}
\hline \multirow[t]{2}{*}{$\mathrm{RT}$ (min) } & \multirow[t]{2}{*}{ Compound name } & \multirow[t]{2}{*}{ Odor description ${ }^{\mathbf{a}}$} & \multicolumn{5}{|c|}{ Percentage (\%) yield } \\
\hline & & & $\begin{array}{l}\text { P. kluyveri } \\
\text { LKC17 }\end{array}$ & $\begin{array}{l}\text { I. orientalis } \\
\text { OSL11 }\end{array}$ & $\begin{array}{l}\text { P. kudriavzevii } \\
\text { OG32 }\end{array}$ & $\begin{array}{l}\text { P. kudriavzevii } \\
\text { ROM } 11\end{array}$ & $\begin{array}{l}\text { C. tropicalis } \\
\text { BOM21 }\end{array}$ \\
\hline 8.59 & 2-Phenylmethyl acetate & Honey, jasmine & $3.86 \pm 0.00$ & ND & ND & ND & ND \\
\hline 23.12 & 1-Methylphenyl butanoate & Jasmin, Apricot & ND & $9.08 \pm 0.84$ & $10.17 \pm 1.45$ & ND & ND \\
\hline 23.88 & Tetramethyl acetate & Waxy, fruity, balsamic & ND & ND & ND & ND & $2.18 \pm 0.00$ \\
\hline 24.69 & Isoamyl decanoate & Waxy, banana, fruity & ND & $4.36 \pm 0.20$ & $4.51 \pm 0.00$ & ND & $7.89 \pm 0.43$ \\
\hline 24.79 & 2-Bromo pentyl butanoate & Fruity & ND & ND & ND & $3.54 \pm 0.28$ & ND \\
\hline 25.12 & 2-Hydroxy,pentyl propanoate & Fruity, apricot, pineapple & ND & ND & ND & $5.97 \pm 0.11$ & ND \\
\hline 26.62 & 10-Undecen-1-yl hexanoate & & $0.40 \pm 0.00$ & $0.32 \pm 0.00$ & ND & ND & ND \\
\hline 28.96 & 2-Ethyl octadecanoate & Waxy & $4.84 \pm 0.02$ & $1.93 \pm 0.00$ & $2.70 \pm 0.00$ & ND & ND \\
\hline \multirow[t]{2}{*}{36.03} & 4-Heptenoic acid ethyl ester & & ND & ND & ND & $5.83 \pm 0.11$ & ND \\
\hline & Total esters (10) & & $9.1(3)$ & $15.69(4)$ & $17.38(3)$ & $15.34(3)$ & $10.07(2)$ \\
\hline
\end{tabular}

ND not detected

ahttp://www.thegoodscentscompany.com/

\section{Screening for phytase production}

The test yeast strains were able to hydrolyze phytate in an enzyme-mediated reaction and utilized the generated myo-inositol phosphate intermediates (IP3-IP5) as sources of phosphorous for growth at $30^{\circ} \mathrm{C}$ for $48 \mathrm{~h}$. This was observed as increased cell density $(600 \mathrm{~nm})$ in respective broth cultures (Fig. 1). The relative growth of yeast strains in phytate supplemented minimal medium compared with phosphate supplemented minimal media was from the range of 91.82 to $99.93 \%$ while the relative growth in phosphate/phytate free minimal medium was less than $7 \%$ for all the yeast strains tested. Pichia kudriavzevii OG32 and C. tropicalis BOM21 had the higher relative growth of $99.88 \%$ and $99.93 \%$ respectively in phytate supplemented minimal medium and they were selected for phytase activity assay.

\section{Phytase activity and stability}

The effects of $\mathrm{pH}$ based on three different buffer systems on extracellular phytase activity of both strains are shown in Fig. 2. The optimum activities were $81.43 \mathrm{U}$ at $\mathrm{pH} 3.6$ and $104.28 \mathrm{U}$ at $\mathrm{pH} 4.6$ for $C$. tropicalis BOM21 and $P$. kudriavzevii OG32 respectively. These indicate that they are acid phytases. Considering extracellular phytase from $P$. kudriavzevii OG3, a decline in activity was recorded as the $\mathrm{pH}$ move toward extreme acidic and neutral pHs. However, another peak (70.3 U) was recorded at pH 5.6 for $C$. tropicalis BOM21. Extracellular phytases from both test strains retained approximately $60 \%$ of optimal activity over a wide range of $\mathrm{pH}(3-8)$ (Fig. 3). The determination of the effect of prevailing temperatures during food processing $\left(20,30\right.$, and $\left.50^{\circ} \mathrm{C}\right)$ and in gastrointestinal tract $\left(37^{\circ} \mathrm{C}\right)$ on the stability of crude phytase extracts showed

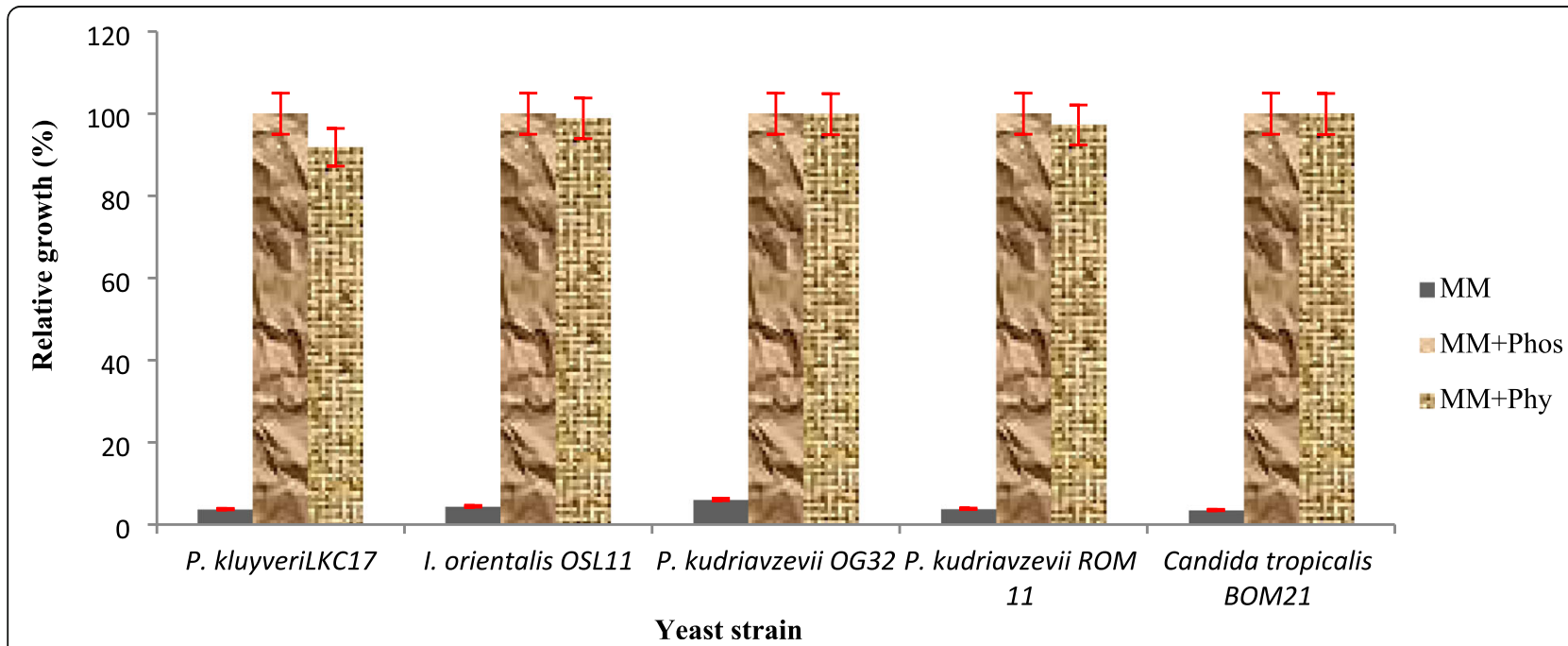

Fig. 1 Relative growth of yeast at $30^{\circ} \mathrm{C}$ after $48 \mathrm{~h}$ cultivation in $\mathrm{MM}$, minimal salts medium; MM+ Phos, minimal salts medium supplemented with $3 \mathrm{~g} \mathrm{~L}^{-1}$ potassium dihydrogen phosphate $\left(\mathrm{KH}_{2} \mathrm{PO}_{4}\right) ; \mathrm{MM}+$ Phy, minimal salts medium supplemented with $3 \mathrm{~g} \mathrm{~L}^{-1}$ sodium phytate 


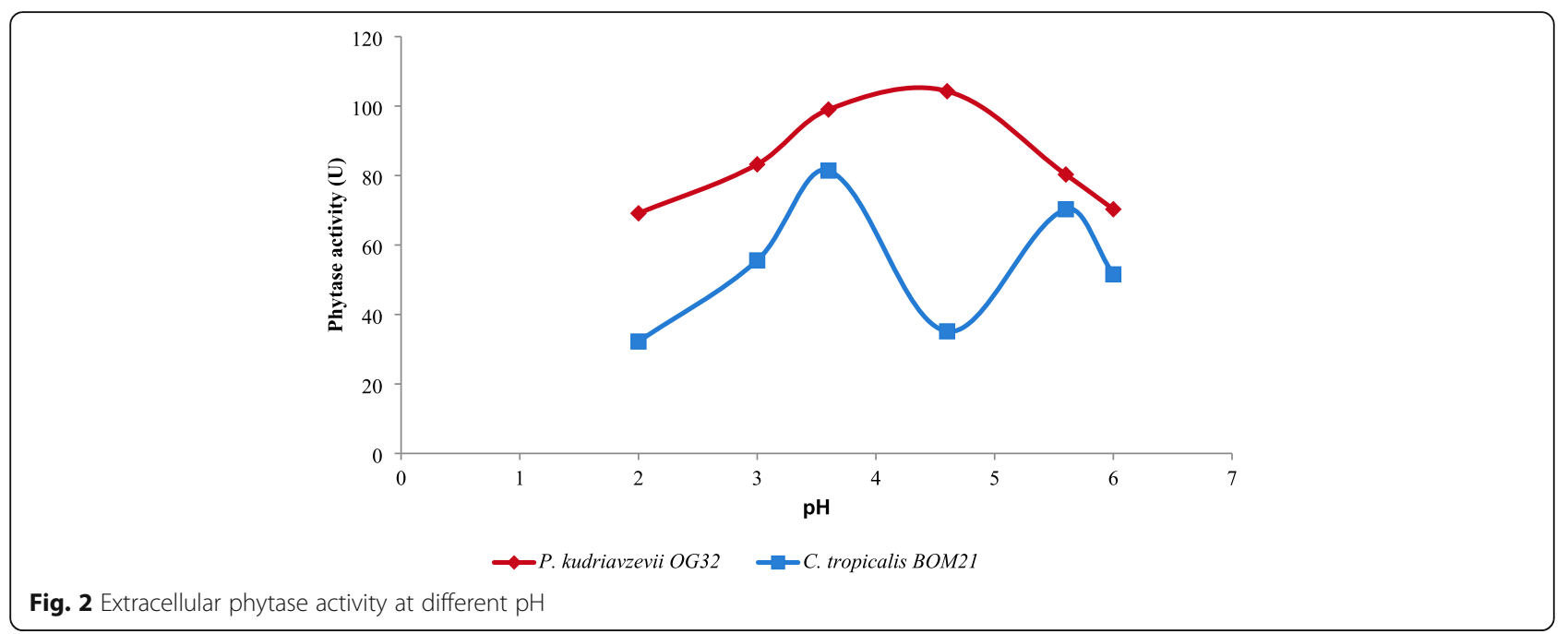

thermal stability (Table 2). Above $80 \%$ activity was retained at test temperatures.

\section{Discussion}

In addition to the probiotic potentials of yeasts, some strains produce valuable metabolites that contribute to the sensory quality and nutritional value of fermented food products [31]. These are important criteria for selection as starter/adjunct cultures [32].

The potentially probiotic yeasts evaluated in this study showed strain-specific potentials to impart pleasant taste and distinct flavor on fermented foods by producing volatile organic compounds such as organic acids, alcohols, and esters. Previous studies reported species and strain specificity in the profile of flavor compounds produced by yeasts [33]. Among the organic acids, Nhexadecanoic acid was encountered in significant proportions in all the test yeast strains. This compound is widespread in yeasts [34]. It is characterized by a creamy fatty flavor and a dairy nuance [35]. In addition, Nhexadecanoic acid is listed as a flavor compound with GRAS status [36]. The production of phenyl ethyl alcohol was recorded in I. orientalis OSL11 and P. kudriavzevii OG32 and ROM11. It is one of the most abundant higher alcohols produced by yeasts, arising from the degradation of phenylalanine through the Ehrlich pathway $[14,18,37]$. Phenyl ethyl alcohol has a sweet floral taste and odor with rosey honey nuances [34]. Several of the higher alcohols identified in this study are listed as GRAS flavor compounds for food applications [36]. Esters are valuable compounds that impart characteristic fruity and flowery notes to fermented beverages [14, 16, 18]. In this study, P. kudriavzevii OG32 is the most dominant ester producer. Prominent among the esters from the strain is benzyl butanoate. It has a fruity aroma, specifically bringing about tropical, pineapple, and apple

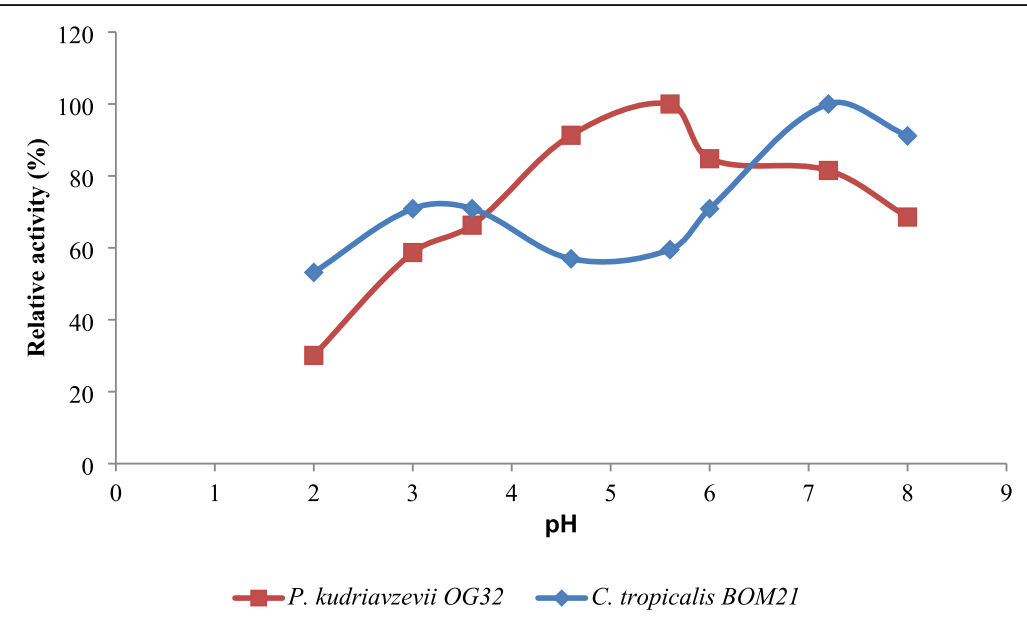

Fig. 3 Extracellular phytase stability at different $\mathrm{pH}$ 
Table 2 Stability of extracellular phytase from yeast strains at different temperature

\begin{tabular}{lll}
\hline $\begin{array}{l}\text { Temperature } \\
\left({ }^{\circ} \mathrm{C}\right)\end{array}$ & \multicolumn{2}{l}{ Relative phytase activity $(\%)$} \\
\cline { 2 - 3 } & P. kudriavzevii OG32 & C. tropicalis BOM21 \\
\hline 20 & 79.25 & 100 \\
30 & 87.42 & 97.14 \\
37 & 100 & 87.14 \\
50 & 90.57 & 91.43 \\
\hline
\end{tabular}

reminiscence [35]. In addition, methyl 2-phenyl acetate from $P$. kluyveri LKC17 and pentadecanoic acid 3 methylbutyl-acetate from I. orientalis OSL11, P. kudriavzevii OG32, and C. tropicalis BOM21 are important esters that were detected in significant proportions. Methyl 2-phenyl acetate is a high strength odor compound that is characterized by honey and jasmine aroma [35]. Similar to the observations from this study, high amounts of acetate esters were reported to be produced by strains of $P$. kluyveri and P. kudriavzevii from some other traditional fermented food sources [38, 39]. Other yeast species including Starmera caribaea and Hanseniaspora guilliermondii were reported to produce high levels of acetate esters with highly desirable flavor [13].

Phytase production has been previously detected and quantified with growth test in liquid medium supplemented with phytate salts as the sole source of phosphate $[25,27]$. The higher relative growths of $P$. kudriavzevii OG32 and C. tropicalis BOM21 are in agreement with previous studies, being an indication of phytase production. Pichia kudriavzevii has been reported to produce cell-bound, intracellular and extracellular phytase $[28,40]$. These species are predominant among the microflora associated with the spontaneous fermentation of several traditional fermented foods.

The maximum activity exhibited by phytases secreted by $C$. tropicalis BOM21 and P. kudriavzevii OG32 in the acidic $\mathrm{pH}$ range of $\mathrm{pH} 3.6-\mathrm{pH} 4.6$ are similar to the optimum pHs of phytases from other yeasts [26, 41, 42]. The technological suitability of the phytase-producing strains is dependent on the stability of secreted phytases to evolving $\mathrm{pH}$ and temperature during food fermentation and gastrointestinal transit. The significant portion of activity retained by phytases investigated over a wide range of $\mathrm{pH}(3-8)$ and temperatures supports the potentials of C. tropicalis BOM21 and P. kudriavzevii OG32 to remove phytate in diverse food fermentation models and the intestine.

\section{Conclusions}

The volatile compounds identified to be produced by yeasts in this study are safe and possess relevant aroma for food use. In addition the phytase secreted by the yeast strains demonstrated activity and stability at conditions that prevail during food fermentation. Therefore, the application of these potentially probiotic yeasts as starter cultures during food fermentation process is a very promising method to enhance the flavor profile and enhance mineral bioavailability in indigenous cerealbased fermented food products.

\section{Abbreviations \\ GC-MS: Gass chromatography-mass spectrometer; ID: Internal diameter; IP6: Inositol hexaphosphate; NIST: National Institute of Standards and Technology; TCA: Trichloroacetic acid; VOC: Volatile organic compound; YPD: Yeast peptone dextrose}

\section{Acknowledgements}

The award of DBT-TWAS Postgraduate Sandwich Fellowship by The Department of Biotechnology (DBT), Government of India, and The World Academy of Sciences (TWAS), Italy to Omotade R. Ogunremi at Central Food Technological Research Institute (CFTRI), Mysore, India is acknowledged.

\section{Authors' contributions}

ORO carried out the experiments and wrote the manuscript. RA and AS supervised the research work and edited the manuscript. All authors read and approved the manuscript.

\section{Funding}

This work was partly funded by The Department of Biotechnology (DBT), Government of India, and The World Academy of Sciences (TWAS), Italy through the award of DBT-TWAS Postgraduate Sandwich Fellowship to Omotade R. Ogunremi to carryout research at Central Food Technological Research Institute (CFTRI), Mysore, India.

The funders had no role in study design, data collection, and analysis, decision to publish, or preparation of the manuscript.

Availability of data and materials

Not applicable.

Ethics approval and consent to participate

Not applicable

Consent for publication

Not applicable

Competing interests

All authors declare that they have no competing interests.

\section{Author details}

${ }^{1}$ Department of Biological Sciences, First Technical University, Ibadan, Nigeria. ${ }^{2}$ Food Microbiology Department, Central Food Technological Research Institute, Mysore, India. ${ }^{3}$ Department of Microbiology, University of Ibadan, Ibadan, Nigeria.

Received: 28 January 2020 Accepted: 30 April 2020

Published online: 08 June 2020

\section{References}

1. FAO/WHO (2001) Report of a joint FAO/WHO expert consultation on evaluation of health and nutritional properties of probiotics in food including powder milk with live lactic acid bacteria. FAO/WHO2, Cordoba

2. Rubio R, Jofré A, Martín B, Aymerich T, Garriga M (2014) Characterization of lactic acid bacteria isolated from infant faeces as potential probiotic starter cultures for fermented. Food Microbio/ 38:303-311. https://doi.org/10.1016/j. fm.2013.07.015

3. Klaenhammer TR, Kullen MJ (1999) Selection and design of probiotics. International Journal of Food Microbiology 50:45-57. https://doi.org/10.1016/ S0168-1605(99)00076-8

4. Kumura H, Tanoue Y, Tsukahara M, Tanaka T, Shimazaki K (2004) Screening of dairy yeast strains for probiotic applications. Journal of Dairy Science 87: 4050-4056. https://doi.org/10.3168/jds.S0022-0302(04)73546-8

5. Pennachia C, Blaiotta G, Pepe O, Villani F (2008) Isolation of Saccharomyces cerevisiae strains from different food matrices and their preliminary selection 
for a potential use as probiotics. J Applied Microbiol 105:1919-1928. https:// doi.org/10.1111/j.1365-2672.2008.03968x

6. Silva T, Reto M, Sol M, Peito A, Peres CM, Peres C, Malcata FX (2011) Characterization of yeasts from Portuguese brined olives, with a focus on their potentially probiotic behavior. LWT - Food Science and Technology 44 1349-1354. https://doi.org/10.1016/j.lwt.2011.01.029

7. Pedersen LL, Owusu-kwarteng J, Thorsen L, Jespersen L (2012) Biodiversity and probiotic potential of yeasts isolated from Fura, a West African spontaneously fermented cereal. Int J Food Microbiol 159:144-151. https:// doi.org/10.1016/j.jifoodmicro.2012.08.016

8. Ogunremi OR, Sanni Al, Agrawal R (2015) Probiotic potentials of yeasts isolated from some cereal-based Nigerian traditional fermented food products. Journal of Applied Microbiology 119:797-808. https://doi.org/10. 1111/jam. 12875

9. Fadda ME, Mossa V, Deplano M, Pisano MB, Cosentino S (2017) Invitro screening of Kluyveromyces strains isolated from Fiore Sardo cheese for potential use as probiotics. LWT - Food Science and Technology 75:100-106. https://doi.org/10.1016/j.lut.2016.08.020

10. Greppi A, Saubade F, Botta C, Humblot C, Guyot JP, Cocolin L (2017) Potential probiotic Pichia kudriavzevii strains and their ability to enhance folate content of traditional cereal-based African fermented food. Food Microbiology 62:169-177. https://doi.org/10.1016/j.fm.2016.09.016

11. Bonatsou S, Karamouza M, Zoumpopoulou G, Mavrogonatou E, Kletsas D, Papadimitriou K, Tsakalidou E, Nychas GJE, Panagou E (2018) Evaluating the probiotic potential and technological characteristics of yeasts implicated in cv, Kalamata natural black olive fermentation. Int J Food Microbiol 271:48-59. https://doi.org/10.1016/j.ijfoodmicro.2018.02.018

12. Gupta S, Abu-ghannam N (2012) Probiotic fermentation of plant based products: possibilities and opportunities. Crit Rev Food Sci Nutrition 52(2): 183-199. https://doi.org/10.1080/10408398.2010.499779

13. Gamero A, Quintilla R, Groenewald M, Alkema W, Boekhout T, Hazelwood L (2016) High-throughput screening of a large collection of non-conventional yeasts reveals their potential for aroma formation in food fermentation. Food Microbiology 60:147-159. https://doi.org/10.1016/j.fm.2016.07.006

14. Grondin E, Sing ASC, James S, Nueno-palop C, François JM, Petit T (2017) Flavour production by Saprochaete and Geotrichum yeasts and their close relatives. Food Chemistry 237:677-684. https://doi.org/10.1016/j.foodchem. 2017.06.009

15. Ravasio D, Carlin S, Boekhout T, Groenewald M, Vrhovsek U, Walther A, Jürgen Wendland J (2018) Adding flavor to beverages with nonconventional yeasts. Fermentation 4(15):1-16. https://doi.org/10.3390/ fermentation4010015

16. Annan NT, Poll I, Sefa dedeh S, Plahar WA, Jakobsen M (2003) Influence of starter culture combinations of Lactobacillus fermentum, Saccharomyces cerevisiae and Candida krusei on aroma in Ghanaian maize dough fermentation. Eur J Food Res Technol 216:377-384. https://doi.org/10.1007/ s00217-003-0692-5

17. Callejon RM, Clavijo A, Ortigueira P, Troncoso AM, Paneque P, Morales ML (2010) Volatile and sensory profile of organic red wines produced by different selected autochthonous and commercial Saccharomyces cerevisiae strains. Analytica Chimica Acta 660:68-75. https://doi.org/10.1016/j.aca.2009. 09.040

18. Wu Q, Xu Y, Chen L (2012) Diversity of yeast species during fermentative process contributing to Chinese Maotai-flavour liquor making. Letters in Applied Microbiology. https://doi.org/10.1111/j.1472-765X.2012.03294.x

19. Andlid TA, Veide J, Sandberg A-S (2004) Metabolism of extracellular inositol hexaphosphate (phytate) by Saccharomyces cerevisiae. Int J Food Microbiol 97:157-169. https://doi.org/10.1016/j.ijfoodmicro.2004.04.016

20. Hellström AM, Vázques-juárez R, Svanberg U, Andlid TA (2010) Biodiversity and phytase capacity of yeasts isolated from Tanzanian togwa. Int J Food Microbiol 136:352-358. https://doi.org/10.1016/j.ijfoodmicro.2009.10.011

21. Brinch-Pedersen H, Borg S, Tauris B, Holm PB (2007) Molecular genetic approaches to increasing mineral availability and vitamin content of cereals. Journal of Cereal Science 46:308-326. https://doi.org/10.1016/j.jcs.2007.02.004

22. Cao L, Wang W, Yang C, Yang Y, Diana J, Yakupitiyage A, Luo Z, li D (2007) Application of microbial phytase in fish feed. Enzyme Microbial Technol 40: 497-507. https://doi.org/10.1016/j.enzmictec.2007.01.007

23. Raghavendra P, Halami PM (2009) Screening, selection and characterization of phytic acid degrading lactic acid bacteria from chicken intestine. International Journal of Food Microbiology 133:129-134. https://doi.org/10. 1016/j.jifoodmicro.2009.05.006
24. Kaur P, Kunze G, Satyanarayana T (2007) Yeast phytases: present scenario and future perspectives. Crit Rev Biotechnol 27:93-109. https://doi.org/10. 1080/07388550701334519

25. Olstorpe M, Schnurer J, Passoth V (2009) Screening of yeast strains for phytase activity. FEMS Yeast Research 9:478-488. https://doi.org/10.1111/j. 1567-1364.2009.00493

26. In M-J, Seo S-W, Kim DC, Oh N-S (2009) Purification and biochemical properties of an extracellular acid phytase produced by the Saccharomyces cerevisiae CY strain. Process Biochemistry 44:122-126. https://doi.org/10.1016/ j.procbio.2008.10.006

27. Nuobariene L, Hansen AS, Jespersen L, Arneborg N (2011) Phytase-active yeasts from grain-based food and beer. Journal of Applied Microbiology 110: 1370-1380. https://doi.org/10.1111/j.1365-2672.2011.04988.x

28. Greppi A, Krych L, Costantini A, Rantsiou K, Hounhouigan DJ, Arneborg N, Cocolin L, Jespersen L (2015) Phytase-producing capacity of yeasts isolated from traditional African fermented food products and PHYPk gene expression of Pichia kudriavzevii strains. International Journal of Food Microbiology 205:81-89. https://doi.org/10.1016/j.ijfoodmicro.2015.04.011

29. Vanaja G, Gotcheva V, Angelov A, Agrawal R (2011) Formation of volatiles and fatty acids of therapeutic importance in the probiotic Lactobacillus plantarum LPcfr adapted to resist GIT conditions. J Food Sci Technol 48(1): 110-113. https://doi.org/10.1007/s13197-010-0110-5

30. Bae HD, Yanke L, Cheng K-J, Selinger LB (1999) A novel staining method for detecting phytase activity. Journal of Microbiological Methods 39:17-22. https://doi.org/10.1016/S0167-7012(99)00096-2

31. Arevalo-villena M, Briones-Perez A, Corbo MR, Sinigaglia M, Bevilacqua A (2017) Biotechnological application of yeasts in food science: starter cultures, probiotics and enzyme production. J Appl Microbiol 123:1360-1372. https://doi.org/10.1111/jam.13548

32. Holzapfel WH (2002) Appropriate starter culture technologies for small-scale fermentation in developing countries. Int J Food Microbiol I 75:197-212. https://doi.org/10.1016/S0168-1605(01)00707-3

33. Grondin E, Sing ASC, Caro Y, Raherimandimby M, Randrianierenana AL, James S, Nueno-palop C, François JM, Petit T (2015) A comparative study on the potential of epiphytic yeasts isolated from tropical fruits to produce flavoring compounds. Int J Food Microbiol 203:101-108. https://doi.org/10. 1016/j.ijfoodmicro.2015.02.032

34. Tehlivets $\mathrm{O}$, Scheuringer K, Kohlwein SD (2007) Fatty acid synthesis and elongation in yeast. Biochimica et Biophysica Acta 1771:255-270. https://doi. org/10.1016/j.bbalip.2006.07.004

35. The Good Scent Company (tgsc) (989. Food additives permitted for direct addition to food for human consumption. http://www. thegoodscentscompany.com/data/rw1009101.html. Accessed 27 February 2014

36. FEMA (2013) Flavour extract manufacturers association of United States. www.fema.com. Accessed 1 December 201

37. Abbas CA (2006) Production of antioxidants, aromas, colours, flavours, and vitamins by yeasts. In: Querol A, Fleet GH (eds) The yeast handbook: yeasts in food and beverages. Springer-Verlag, Berlin Heidelberg, pp 285-334

38. Holt S, Mukherjee V, Lievens B, Verstrepen KJ, Thevelein JM (2018) Bioflavoring by non-conventional yeasts in sequential beer fermentations. Food Microbiology 72:55-66. https://doi.org/10.1016/j.fm.2017.11.008

39. Zheng X, Li K, Shi X, Ni Y, Li B, Zhuge B (2018) Potential characterization of yeasts isolated from Kazak artisanal cheese to produce flavoring compounds. MicrobiologyOpen 7:533. https://doi.org/10.1002/mbo3.533

40. Hellström A, Gvirist L, Svanberg U, Vilg JV, Andlid T (2015) Secretion of noncell-bound phytase by the yeast Pichia kudriavzevii TY13. J Appl Microbiol 118:1126-1136. https://doi.org/10.1111/jam.12767

41. Caputo L, Visconti A, De angelis M (2015) Selection and use of a Saccharomyces cerevisae strain to reduce phytate content of wholemeal flour during bread-making or under simulated gastrointestinal conditions. LWT - Food Sci Technol 63:400-407. https://doi.org/10.1016/j.Iwt.2015.03.058

42. Kłosowski G, Mikulski D, Jankowiak O (2018) Extracellular phytase production by the wine yeast $S$. cerevisiae (Finarome Strain) during submerged fermentation. Molecules 23(848). https://doi.org/10.3390/molecules23040848

\section{Publisher's Note}

Springer Nature remains neutral with regard to jurisdictional claims in published maps and institutional affiliations. 